\title{
COORDINACIÓN DE LA LEY DE COOPERACIÓN JURÍDICA INTERNACIONAL EN MATERIA CIVIL CON LA LEGISLACIÓN ESPECIAL
}

\author{
Pedro Alberto De Miguel Asensio \\ Catedrático de Derecho internacional privado \\ Universidad Complutense de Madrid
}

SUMARIO: 1. NORMAS ESPECIALES Y ÁMBITO DE APLICACIÓN DE LA NUEVA LEY.2. APLICACIÓN JUDICIAL DEL DERECHO EXTRANJERO.-3. RECONOCIMIENTO INCIDENTAL Y EXEQUÁTUR.-4. CONDICIONES DEL RECONOCIMIENTO.

\section{NORMAS ESPECIALES Y ÁMBITO DE APLICACIÓN DE LA NUEVA LEY}

1. La aplicación de la Ley 29/2015, de 30 de julio, de cooperación jurídica internacional en materia civil (LCJIC) se halla condicionada por su carácter subsidiario, previsto expresamente en su art. 2, relativo a las fuentes. Dejando ahora a un lado la repercusión de la primacía del Derecho de la UE y la aplicación preferente de las normas contenidas en los convenios internacionales en los que España es parte, que contempla el art. 2.a) LCJIC; el otro elemento determinante del carácter subsidiario de la ley se relaciona con su naturaleza de legislación marco general, de aplicación supletoria respecto de las que el art. 2.b) denomina normas especiales del Derecho interno.

2. De acuerdo con su Preámbulo, el carácter subsidiario de la LCJIC previsto en ese art. 2.b) responde al principio de especialidad. La enumeración no exhaustiva de las normas que se consideran especiales «en materia de cooperación jurídica internacional en materia civil y mercantil», de modo 
que prevalecen sobre la nueva ley, aparece recogida en la DA $1 .{ }^{\mathrm{a}} \mathrm{LCJIC}$, que incluye las siguientes: $a$ ) arts. 199 a 230 de la Ley Concursal; $b$ ) arts. 25 a 31 de la Ley de Adopción Internacional; c) arts. 94 a 100 de la Ley 20/2011 del Registro Civil (LRC de 2011); d) art. 67.1 de la Ley General para la Defensa de los Consumidores y Usuarios (LGDCU); e) art. 46 de la Ley 60/2003, de Arbitraje; f) normas de la Ley y Reglamento Hipotecarios, así como del Código de Comercio y del Reglamento del Registro Mercantil, reguladoras de la inscripción de documentos extranjeros en cuanto sean compatibles con la LCJIC, y g) normas de Derecho internacional privado contenidas en la Ley 15/2015, de Jurisdicción Voluntaria (LJV).

Si bien del mencionado art. 2.c) LCJIC se deriva que todas esas normas - y eventualmente otras que puedan ser consideradas especiales- resultan de aplicación preferente, la coordinación de la LCJIC con alguna de esas leyes especiales, así como la interpretación conjunta de estos diversos textos legales no están exentas de dificultades, lo que es consecuencia de la creación de un marco normativo excesivamente complejo, como ilustra la situación creada en los sectores que se reseñan a continuación.

\section{APLICACIÓN JUDICIAL DEL DERECHO EXTRANJERO}

3. En relación con la prueba del Derecho extranjero, básicamente la LCJIC se remite a la LEC —en la que continúa siendo determinante el art. 281.2-y, con una redacción cuestionable en la que se destaca el carácter excepcional de la imposibilidad de probar el Derecho extranjero, establece el criterio derivado de la jurisprudencia del Tribunal Constitucional, en el sentido de que cuando no haya podido probarse el Derecho extranjero procede aplicar en su lugar el Derecho español. Por lo demás, el art. 33 LCJIC se limita a prever que los órganos jurisdiccionales españoles determinarán el valor de la prueba del Derecho extranjero de acuerdo con las reglas de la sana crítica (apdo. 2), y que para ellos ningún informe o dictamen sobre Derecho extranjero tendrá carácter vinculante (apdo. 4).

4. La dispersión de las normas de nuestro sistema de Derecho internacional privado, que las recientes reformas han consolidado, se ha traducido en que de manera injustificada este sea uno de los ámbitos en los que ahora supuestamente existe legislación específica. Tal normativa tiene su origen en la introducción en la reforma de la LGDCU llevada a cabo por la Ley 3/2014, de 27 de marzo, de un inciso final en el art. 67.1 LGDCU, según la cual: «Cuando no se haya podido determinar el contenido de la ley extranjera, se aplicará subsidiariamente la ley material española». Se trata de un inciso cuya adición en esa norma resultaba cuestionable, pues aunque su contenido pueda resultar apropiado, la inclusión en una disposición específica en materia de contratos de consumo no era acertada, al tratarse de un aspecto clave en la aplicación de la ley extranjera, que se proyecta sobre el conjunto de las materias de Derecho privado, sin que en el sector de los contratos de 
consumo estuviera justificada una solución diferenciada, lo que aconseja su regulación en una norma de alcance mucho más general.

Ciertamente la solución prevista en el art. 67.1 LGDCU recogió la que, aunque sin estar establecida legalmente, en realidad era ya la regla general en nuestro sistema, en el que no resulta necesario prever una pluralidad de regímenes en esta materia, uno de ellos supuestamente específico de los contratos de consumo. El tratamiento que en materia de ley aplicable establece el Reglamento Roma I y el mecanismo de protección de los consumidores que configura refuerzan esa conclusión. Resulta llamativo que el párr. 3. ${ }^{\circ}$ del apartado V del Preámbulo de la LCJIC admita de manera expresa que en esta materia la legislación especial pueda prever soluciones iguales a la normativa general, con referencia específica a la legislación sobre consumo. El art. 33 (Título II) LCJIC va referido a la prueba del Derecho extranjero ante los órganos jurisdiccionales, ámbito en el que la única legislación especial es el referido inciso del art. 67.1 LGDCU y que existen buenas razones para considerar que no establece una solución distinta a la general recogida ahora en el art. 33 LCJIC, lo que cuestiona la necesidad de mantener en vigor el inciso sobre el particular de la LGDCU. En todo caso, es de lamentar que en el texto del art. 33.3 LCJIC no se haya reproducido la formulación más acertada de ese inciso de la LGDCU.

\section{RECONOCIMIENTO INCIDENTAL Y EXEQUÁTUR}

5. El art. 41 LCJIC, relativo al ámbito de aplicación de su Título V sobre reconocimiento y ejecución, establece que son susceptibles de reconocimiento y ejecución, conforme a las disposiciones de ese Título, «las resoluciones extranjeras firmes recaídas en un procedimiento contencioso» así como «las resoluciones extranjeras definitivas adoptadas en el marco de un procedimiento de jurisdicción voluntaria». Con respecto a estas últimas, se plantea la necesidad de coordinar la aplicación de las normas generales de la LCJIC con las de la LJV, aprobada tan solo unos días antes que la LCJIC y cuyos arts. 11 y 12 regulan la inscripción y eficacia de las resoluciones, actos y expedientes extranjeros de jurisdicción voluntaria, al tiempo que su DA 3. ${ }^{\text {a }}$ contempla la inscripción de documentos públicos extranjeros.

El término «resolución» se define en el art. 43 LCJIC, en línea con los reglamentos de la UE, de manera muy amplia, lo que se ve reforzado por la inclusión de las resoluciones procedentes de autoridades no judiciales que tengan atribuciones análogas a las de las autoridades judiciales. Aunque el art. 43.c) LCJIC va referido de manera imprecisa a «atribuciones análogas a las de las autoridades judiciales de un Estado», cabe entender que España debe ser la referencia, como Estado requerido, al apreciar cuáles son las atribuciones propias de las autoridades judiciales, como, por ejemplo, aunque en un ámbito distinto, hacen el art. 11.3 LJV y el art. 96.3 LRC de 2011.

6. Presenta singular importancia la admisión en la LCJIC del llamado tradicionalmente reconocimiento automático o sin procedimiento especial, 
en el que el reconocimiento es posible sin necesidad de tramitar el exequátur. Frente a la situación prevalente anteriormente en el régimen de fuente interna, la LCJIC admite el reconocimiento incidental directamente por parte del juez que conozca de un procedimiento judicial en el que se plantee el reconocimiento de una resolución extranjera (art. 44.2 LCJIC). Con respecto al reconocimiento incidental en el marco de un procedimiento judicial, la LCJIC no requiere la tramitación de un incidente conforme a los arts. 388 y ss. LEC, de modo que puede decidirse de manera más sencilla directamente en el marco del concreto procedimiento en el que se solicite el reconocimiento, lo que facilita la eficacia de las resoluciones extranjeras. Como es propio del reconocimiento sin procedimiento especial, el art. 44.2 LCJIC prevé que la eficacia del reconocimiento incidental queda limitada a lo resuelto en el proceso principal, por lo que no impide que se solicite el exequátur, como procedimiento que permite obtener una declaración general de reconocimiento.

Asimismo, la LCJIC establece que no se requiere procedimiento especial para la inscripción «en los Registros españoles de la Propiedad, Mercantil y de Bienes Muebles de las resoluciones judiciales extranjeras» (art. 59 LCJIC). También el art. 96.2 LRC de 2011 contempla la inscripción de resoluciones extranjeras ante el encargado del Registro Civil sin necesidad de procedimiento especial o exequátur, estableciendo un régimen de condiciones específico. En todo caso, la entrada en vigor de esta disposición no se ha producido de manera coordinada con la modificación del régimen general de reconocimiento, pues de acuerdo con la DF $10 .^{\text {a }}$ de la LRC de 2011, modificada por la LJV, la LRC entrará en vigor el 30 de junio de 2017.

7. En este contexto, podría haber sido acertado establecer en una disposición expresa de la LCJIC con carácter general de manera clara la posibilidad de reconocimiento sin procedimiento especial. Tal posibilidad se desprende, entre otros elementos, del contraste entre el art. 44.1 LCJIC - relativo al reconocimiento- y su art. 50.1 que, a diferencia del anterior, hace depender en todo caso la ejecutabilidad de las resoluciones extranjeras de que se haya obtenido su exequátur. En el apartado VIII del Preámbulo de la LCJIC se hace referencia a que en «el Título V se opta por el mantenimiento del exequátur como procedimiento especial cuyo objeto es declarar, a título principal, el reconocimiento de una resolución judicial extranjera y, en su caso, autorizar su ejecución. Ello contrasta con lo establecido en los Reglamentos de la Unión Europea...». Ahora bien, cabe entender que esa referencia no impide apreciar que el criterio general en la LCJIC es la posibilidad de reconocimiento incidental sin procedimiento especial (exequátur), mientras que la declaración de ejecutividad sí se subordina al previo exequátur, a diferencia del modelo de supresión del exequátur adoptado en ciertos Reglamentos de la UE, muy especialmente en el Reglamento Bruselas I bis. A este último aspecto parece ir referido el inciso reseñado del Preámbulo acerca del mantenimiento del exequátur en la nueva ley.

8. La inscripción de resoluciones judiciales extranjeras en los registros públicos españoles aparece regulada en el art. 59 LCJIC, que va referido a la 
«inscripción en los Registros españoles de la Propiedad, Mercantil y de Bienes Muebles». Conforme a esta norma el reconocimiento se configura como presupuesto para la inscripción, pero es posible el reconocimiento sin necesidad de procedimiento especial, directamente por el registrador, que el art. 59.2 LCJIC denomina «reconocimiento incidental», al igual que cuando se plantee en un procedimiento judicial (art. 44.2 LCJIC, ya mencionado). Los motivos de denegación del reconocimiento son también, en este caso, los previstos con carácter general en el art. 46.1 LCJIC.

Aunque el régimen establecido en el art. 59 LCJIC para la inscripción en los Registros de la Propiedad, Mercantil y de Bienes Muebles (art. 59.1) responde a un modelo similar al previsto en el art. 96 de la LRC de 2011, parece cuestionable la conveniencia de la pluralidad de normas en este ámbito. En particular, llama la atención que los motivos de denegación del reconocimiento incidental registral - al menos formalmente- no coincidan en esas dos normas.

9. Por otra parte, como ha quedado señalado, el art. 41 de la LCJIC refleja que la nueva ley opta por un modelo en el que las reglas de reconocimiento y ejecución son en principio comunes para las resoluciones recaídas en procedimientos contenciosos y las adoptadas en procedimientos de jurisdicción voluntaria. Ahora bien, de manera preferente a la LCJIC se aplica la legislación especial, condición que la DA 1. ${ }^{\text {a }}$ de la LCJIC expresamente atribuye a las normas de Derecho internacional privado contenidas en la LJV. Por consiguiente, en particular, los arts. 11 y $12 \mathrm{LJV}$, que contienen «normas específicas para el reconocimiento y eficacia en España de los actos de jurisdicción voluntaria acordados por autoridades extranjeras» (en los términos del apartado X del Preámbulo de la LJV) son de aplicación preferente a las normas sobre reconocimiento y ejecución de la LCJIC.

Los arts. 11 y $12 \mathrm{LJV}$ se caracterizan por su poca precisión y falta de rigor terminológico. En todo caso, el art. $11 \mathrm{LJV}$, así como los apartados 1 y 2 del art. $12 \mathrm{LJV}$, establecen que el reconocimiento es presupuesto de la inscripción registral de las resoluciones definitivas (o firmes). El reconocimiento puede tener lugar por vía incidental ante el encargado del Registro, si bien este no será necesario cuando se haya obtenido previamente el exequátur. En definitiva, en relación con la posibilidad de reconocimiento incidental registral y con el eventual recurso al exequátur, el criterio establecido en el art. 11 LJV coincide con el previsto en la LCJIC, cuyas reglas son aplicables a lo no previsto en la LJV o la normativa registral, por ejemplo, en relación con la tramitación del proceso de exequátur.

Con respecto a las inscripción de documentos públicos extranjeros extrajudiciales (art. 60 LCJIC), debe tenerse en cuenta lo dispuesto en la DA 3. ${ }^{\text {a }}$ LJV, dedicada específicamente a la inscripción en los registros públicos de documentos públicos extranjeros no dictados por un órgano judicial, relevante en relación con las resoluciones y actos de jurisdicción voluntaria en materias cuya competencia correspondería, según la LJV, al conocimiento de autoridades (españolas) no judiciales. 
10. El exequátur se configura en el art. 42 LCJIC como el procedimiento para declarar a título principal el reconocimiento de una resolución extranjera y, en su caso, autorizar su ejecución en España. Es además el procedimiento a disposición de quien pretenda una declaración de no reconocimiento de una resolución extranjera con base en que incurre en alguna de las causas de denegación del reconocimiento del art. 46 LCJIC. La declaración de reconocimiento (o no reconocimiento) a título principal no produce los limitados efectos que son propios del reconocimiento incidental, sino que el auto de exequátur tiene eficacia vinculante general. Por otra parte, la tramitación del exequátur es presupuesto necesario para que una resolución extranjera pueda desplegar en España su eficacia ejecutiva (art. 50 LCJIC). El art. 52 LCJIC establece las reglas para determinar el Juzgado de Primera Instancia o de lo Mercantil competente para conocer del exequátur y el proceso de exequátur aparece regulado en el art. 54 LCJIC.

Entre las normas especiales, en materia de arbitraje la DA 1. ${ }^{a}$ LCJIC incluye únicamente el art. 46 de la Ley 60/2003, de 23 de diciembre, de Arbitraje, relativo al exequátur de laudos arbitrales. No obstante, pese a que solo se mencione esa norma, otras disposiciones de nuestro ordenamiento que prevén un trato diferenciado para los laudos arbitrales extranjeros resultarán de aplicación preferente a las reglas generales sobre exequátur de la LCJIC, como sucede con las relativas a la competencia para conocer del exequátur de laudos arbitrales, atribuida por el art. 73.1.a) LOPJ a los Tribunales Superiores de Justicia, y eventualmente al régimen de recursos contra el auto de exequátur. Con respecto a esta última cuestión, la derogación llevada a cabo por LCJIC de las normas de la LEC de 1881 alcanza a su art. 955, que incluía la precisión de que no cabe ulterior recurso frente a la decisión sobre el reconocimiento de los laudos arbitrales extranjeros. No obstante, tratándose de una materia atribuida a los Tribunales Superiores de Justicia, a diferencia de la competencia para conocer de las solicitudes de exequátur de resoluciones judiciales extranjeras que corresponde a los Juzgados de Primera Instancia y los Juzgados de lo Mercantil, cabe entender que tras la reforma tampoco le es aplicable el régimen de recursos previsto en el art. 55 LCJIC, según el cual frente al auto de exequátur cabe recurso de apelación y, eventualmente, recurso extraordinario por infracción procesal o recurso de casación.

\section{CONDICIONES DEL RECONOCIMIENTO}

11. Entre las principales carencias del régimen previo en materia de reconocimiento y ejecución de resoluciones extranjeras, contenido en la LEC de 1881, se encontraba la deficiente formulación de los motivos de denegación del reconocimiento y ejecución, en concreto en su art. 954, destacando la ausencia de cualquier referencia al control de la competencia del tribunal de origen. Frente a esta situación, el enfoque fragmentario que lastra la revisión de nuestro sistema de Derecho internacional privado ha llevado a la aprobación en los últimos años de una pluralidad de normas que recogen 
este control. Así, en la actualidad, junto al régimen general del nuevo art. 46 LCJIC, existen normas especiales que prevén el control de la competencia del tribunal de origen en otras leyes consideradas especiales por la LCJIC, como la Ley Concursal (art. 220.1.3. ${ }^{\circ}$ ), la Ley de Adopción Internacional (arts. 26.1.1. ${ }^{\circ}$ y 34.1.2. ${ }^{\circ}$ reformados por la Ley 26/2015, de 28 de julio), la LRC de 2011 [art. 96.2.2. b) ] y la LJV [art. 12.3.a)].

La coexistencia de un cúmulo tan elevado de normas que pretenden regular con los mismos criterios una misma cuestión - aunque en ámbitos distintos- pero lo hacen de manera descoordinada no está exenta de dificultades.

12. El art. 46.1.c) LCJIC regula el control de la competencia del tribunal de origen, estableciendo que la resolución extranjera no se reconocerá cuando «se hubiere pronunciado sobre una materia respecto a la cual fueren exclusivamente competentes los órganos jurisdiccionales españoles o, respecto a las demás materias, si la competencia del juez de origen no obedeciere a una conexión razonable». Incluye además la presunción de que existe una conexión razonable con el litigio cuando el órgano extranjero haya basado su competencia judicial internacional «en criterios similares a los previstos en la legislación española».

Se trata de una norma que establece un estándar apropiado, pues parte de que este motivo de denegación del reconocimiento concurre cuando entre el litigio y el Estado de origen no exista una conexión razonable - lo que normalmente será el caso cuando la competencia se hubiera basado únicamente en un fuero exorbitante-, asegura expresamente el respeto a las competencias exclusivas de los tribunales españoles y utiliza la bilateralización de nuestras reglas de competencia (básicamente ahora las establecidas en los arts. 22 a 22 nonies LOPJ) como un criterio no determinante, de modo que no excluye que pueda apreciarse la existencia de una conexión razonable en otras situaciones. Por otra parte, tampoco debe descartarse que, pese a estar vinculado el litigio con el Estado de origen, pueda llegarse a la conclusión de que no existía conexión razonable a estos efectos; por ejemplo, en situaciones en las que las partes se habían sometido válidamente a los tribunales de otro Estado.

13. Ahora bien, la LCJIC incorpora una regla adicional sobre control de la competencia del tribunal de origen. En concreto, la segunda cautela que en relación con el reconocimiento de las resoluciones resultantes del ejercicio de acciones colectivas prevé la LCJIC tiene que ver precisamente con este control. En concreto, el art. 47.2 LCJIC establece que esas resoluciones no se reconocerán «cuando la competencia del órgano jurisdiccional de origen no se hubiera basado en un foro equivalente a los previstos en la legislación española». Según el apartado VIII del Preámbulo de la LCJIC esta redacción implica un control de la competencia del juez de origen más estricto que el establecido con carácter general en el art. 46.1.c) LCJIC, pues la exigencia de equivalencia entre las reglas de competencia supone precisamente que no baste la mera semejanza. 
Llama la atención que el art. 96.2.2. ${ }^{\circ}$ b) de la LRC de 2011 en relación con el reconocimiento por el encargado del Registro Civil, como presupuesto de la inscripción, exige que se verifique que: «El Tribunal de origen hubiera basado su competencia judicial internacional en criterios equivalentes a los contemplados en la legislación española». A la luz de la redacción de esta norma, cabe preguntarse si el estándar exigido en este caso coincide con el del art. 46.1.c) LCJIC o con el del art. 47.2 LCJIC, pues se aprecia que su redacción sobre este particular, al utilizar el término «equivalentes» básicamente coincide con la adoptada por el art. 47.2 con el propósito de establecer un control más estricto. Similar cuestión puede plantearse en relación con el art. 220.1.3. ${ }^{\circ}$ de la Ley Concursal, que utiliza un término similar, al contemplar como requisito para que una resolución judicial extranjera se reconozca: "Que la competencia del tribunal o de la autoridad que haya abierto el procedimiento de insolvencia esté basada en alguno de los criterios contenidos en el art. 10 de esta Ley o en una conexión razonable de naturaleza equivalente». ¿El estándar exigido en estos casos coincide con el del art. 46.1.c) LCJIC o con el del art. 47.2 LCJIC? Aunque la LRC de 2011 y la Ley Concursal empleen el término «equivalente», al que el Preámbulo de la LCJIC atribuye el significado antes señalado, parece razonable entender que el estándar de control aplicable en ambas normas coincide con el del art. 46.1.c) LCJIC, pues el art. 47.2 LCJIC obedece al propósito de establecer una cautela específica para las resoluciones derivadas de acciones colectivas, que no está presente en el art. 96.2.2. ${ }^{\circ}$ ) de la LRC de 2011, ni en el art. 220.1.3. ${ }^{\circ}$ de la Ley Concursal.

14. La comparación del art. 46.1 LCJIC con otras normas recientes de nuestro ordenamiento que cumplen una función similar pone de relieve algunas carencias adicionales en la formulación de la nueva ley. Conforme al art. 46.1.a) LCJIC, las resoluciones extranjeras no se reconocerán «(c)uando fueran contrarias al orden público». Aunque no se haya utilizado, como hubiera sido deseable, la terminología consolidada en la práctica internacional, que hace referencia a que la contradicción sea «manifiesta», debe afirmarse también en el régimen de fuente interna el carácter excepcional del orden público, que impone su aplicación restrictiva. De hecho, el art. 96.2.2. ${ }^{\circ} \mathrm{c}$ ) de la LRC de 2011 sí hace referencia como requisito del reconocimiento incidental registral a que la resolución extranjera no resulte «manifiestamente incompatible con el orden público español». Una formulación semejante cabe encontrar en el art. 12.3.c) de la LJV, más acertado en este aspecto puntual que el art. 46.1 LCJIC. En todo caso, las diferencias de redacción no deben implicar un distinto alcance de la excepción de orden público en esas normas.

15. Frente al régimen general de la LCJIC, la especialidad de la normativa de reconocimiento de las resoluciones firmes de jurisdicción voluntaria previsto en la LJV radica fundamentalmente en que el art. $12.3 \mathrm{LJV}$ incorpora una relación propia de causas de denegación del reconocimiento de los actos de jurisdicción voluntaria firmes, que, pese a su imprecisa terminología, cabe entender que establece el régimen especial de reconocimiento en España de las resoluciones extranjeras de jurisdicción voluntaria, en particular de aque- 
llas recaídas en materias cuya competencia corresponda, según la LJV, al conocimiento de órganos jurisdiccionales, de conformidad con lo dispuesto en el art. 1.1. De los controles previstos en el art. 12.3 LJV (como el control de la competencia del órgano de origen y de los derechos de defensa de los implicados) se desprende que se trata típicamente de resoluciones que producen efectos susceptibles de reconocimiento en sentido propio. Las carencias de esa relación propia de causas de denegación se acentúan al tener en cuenta que se halla incluida en una ley que fue adoptada tan solo unos días antes que la LCJIC. Con carácter general, hubiera sido deseable una mejor coordinación de la LJV con las normas generales sobre reconocimiento de resoluciones extranjeras adoptadas prácticamente de manera simultánea en la LCJIC, que facilitaría la comprensión y aplicación de nuestro sistema.

En contraste con el art. 46.1 LCJIC, el art. 12 LJV enumera cuatro causas de denegación del reconocimiento: control de la competencia internacional de la autoridad extranjera, control del respeto a los derechos de defensa de los implicados, control del orden público y, añadido en la tramitación parlamentaria, violación de un derecho fundamental o libertad pública de nuestro ordenamiento. Con respecto al control de la competencia y del orden público, como ha quedado ya reseñado, llama la atención que la formulación de esas causas de denegación, aunque similar en su orientación, sea distinta de las del art. 46.1 LCJIC. Además, parece innecesario que en la tramitación parlamentaria de la LJV se añadiera, justo a continuación del control de orden público, un apartado d) que prevé la denegación del reconocimiento en España en caso de «violación de un derecho fundamental o libertad pública de nuestro ordenamiento jurídico». Como precisamente tales derechos y libertades son el núcleo del contenido del orden público español, el añadido del apartado d) parece injustificado, habida cuenta además de que el control de las garantías procesales viene ya recogido en el apartado $b$ ) del art. $12 \mathrm{LJV}$.

Más grave resulta la ausencia en el art. $12 \mathrm{LJV}$ de toda referencia a un control sí previsto en el art. 46 LCJIC y que en algunos casos puede resultar relevante también en el ámbito de la jurisdicción voluntaria, como es el de la no contradicción con resoluciones eficaces o procedimientos pendientes (iniciados con anterioridad) en España. En caso necesario, no debería descartarse el eventual recurso para suplir esta carencia a la norma sobre orden público del art. 12.3 LJV o la aplicación analógica de lo dispuesto en el art. 46 LCJIC. La coherencia de nuestro ordenamiento jurídico también resulta menoscabada cuando se otorga eficacia a una resolución extranjera contradictoria con una situación establecida por una resolución española de jurisdicción voluntaria de carácter constitutivo. Esta conclusión no impide apreciar que la peculiar modificabilidad de las resoluciones que es característica del ámbito típico de la jurisdicción voluntaria se proyecta sobre el significado de esta condición del reconocimiento. La menor estabilidad de tales resoluciones se corresponde en ciertos ámbitos con que las mismas tienen lugar en el contexto de una actividad asistencial duradera, que no finaliza con la resolución sino que debe ser adaptada atendiendo a los cambios de circunstancias. Ciertamente, 
la relación entre contradicción de la resolución extranjera con la nacional, que excluye su reconocimiento, y modificación de esta a través de aquella, que no lo impide, presenta particular relevancia en el ámbito de la jurisdicción voluntaria, pero no impide apreciar que el control de la no contradicción con resoluciones eficaces en España resulta también necesario cuando se pretende el reconocimiento de una resolución de jurisdicción voluntaria.

Palabras clave: Derecho extranjero, resolución, reconocimiento, exequátur.

Keywords: foreign law, judgment, recognition, exequatur. 